\title{
El Conversatorio Universitario de 1919 y su significación histórica
}

\begin{abstract}
RESUMEN
A pocos años de la conmemoración del centenario de la independencia nacional, un grupo de estudiantes de la Universidad de San Marcos inauguró un ciclo de conferencias que sería conocido como el Conversatorio Universitario. Esta actividad académica, impulsada por Raúl Porras Barrenechea, proponía, desde la historia, nuevas aproximaciones a la época de la Emancipación en el período $1800-1825$.

Las actividades del Conversatorio Universitario se iniciaron en junio de 1919. Sus participantes eran jóvenes estudiantes, quienes expusieron avances de las investigaciones que venían desarrollando. En sus trabajos, la independencia del Perú fue abordada desde diferentes perspectivas. A partir de entonces, los ponentes — miembros de la nominada «Generación del Centenario»— cumplirían destacada labor en la vida intelectual del país; éstos fueron: Raúl Porras, Jorge Guillermo Leguía, Luis Alberto Sánchez y Manuel G. Abastos.

Durante la realización del Conversatorio Universitario, acontecieron dos hechos que dejarían una profunda huella en la vida peruana: la Reforma Universitaria y el ascenso al poder de Augusto B. Leguía.
\end{abstract}

Palabras clave: Conversatorio Universitario; Independencia del Perú; Historiografía; Historia del Perú; Reforma Universitaria.

\section{The Conversatorio Universitario (University Discussion) of 1919 and its historical significance}

\begin{abstract}
A few years before the commemoration of the centennial of the national independence, a group of students from the San Marcos University opened a conference cycle which would be known as the Conversatorio Universitario (University Discussion). This academic activity, endorsed by Raul Porras Barrenechea proposed, from a historical perspective, new approaches to the Emancipation era during the $1800-1825$ period.

Conversatorio Universitario activities began in June 1919. Its participants were young students, who presented their progress in research being developed. In their research the independence of Peru was approached from different points of view. Subsequently, the commentators - members of the named "Centennial Generation»- would accomplish a distinguished endeavor in the country's intellectual life; among there were Raul Porras, Jorge Guillermo Leguia, Luis Alberto Sanchez and Manuel G. Abastos.

During the enactment of the Conversatorio Universitario two events took place which would leave a profound mark in Peruvian life: the University Reform and the rise to power of Augusto B. Leguia.
\end{abstract}

KeYwords: Conversatorio Universitario; Independence of Peru; Historiography; History of Peru; University Reform. 


\section{Introducción}

E n 1919, en vísperas de conmemorarse el centenario de la independencia del Perú, se hubo de celebrar en Lima una actividad académica de significación cultural en nuestra historia republicana. Un círculo estudiantil de los claustros de la Universidad de San Marcos organizó un ciclo de charlas que sería bautizado como el Conversatorio Universitario. Este evento pretendía contribuir a la celebración de dicha efeméride, arrojando nuevas luces sobre la época de la Emancipación. Los temas, objeto de las disertaciones, fueron diversos y correspondieron a cuestiones de naturaleza social, literaria e ideológica en el marco temporal comprendido entre la segunda mitad del siglo XviII y el primer cuarto de la centuria siguiente.

Promovido por Raúl Porras Barrenechea, el Conversatorio Universitario inauguró sus actividades en junio de 1919. En éste participaron intelectuales noveles que, desde aquellos días, ocuparían un señalado lugar en las letras peruanas. Tal plantel estuvo conformado por caracterizados elementos de aquella generación, conocida como la "Generación del Centenario», a causa de que su advenimiento ocurrió en 1921, año en que se conmemoraba el centésimo aniversario de la proclamación de la Independencia.

¿Cuáles fueron las aportaciones de este encuentro académico a la reflexión histórica en torno a la Emancipación peruana? Su principal contribución hallase en la apertura de nuevas perspectivas de investigación. Los historiadores de fines del siglo XIX y principios del $\mathrm{xx}$ dirigieron preferentemente su atención hacia los aspectos políticos, militares e ideológicos de la revolución de independencia. En el caso del Convesatorio, los temas abordados comprendieron materias que habían sido desdeñadas por la historiografía precedente: la vida social en Lima en las postrimerías de la Colonia, las expresiones literarias y el mundo de las ideas en tiempos de la Emancipación. Los enfoques innovadores y la ampliación temática de los trabajos presentados representaron una orientación renovadora en los estudios sobre aquella etapa de la historia del Perú.

\section{Contexto sociopolítico}

En el año 1919 sobrevinieron episodios en la vida nacional que definirían nuevos horizontes políticos. Gobernaba el Perú, en su segundo mandato, José Pardo y Barreda (1915-1919), representante del Partido Civil —que conducía los destinos del Perú desde 1899-. El último año de su gobierno se vio turbado por sucesos de intensa agitación social. En mayo de 1919, se organizó en Lima y el puerto del Callao una huelga obrera a causa del incremento del costo de vida. El Comité Obrero de Lima y su sección "comité pro-abaratamiento de las subsistencias» convocó a los artesanos y obreros fabriles para protestar de manera pública. Los manifestantes demandaban que, junto con la reducción de precios de los alimentos y del transporte, se cumpliera estrictamente la jornada de ocho horas — que por Decreto Supremo fue sancionada el 15 de enero de ese año-. Al no ser atendidas sus demandas, el movimiento de los trabajadores declaró un paro general el 27 de mayo, que se prolongó por los siguientes seis días. Hubo situaciones de exacerbada convulsión social en las que se perpetraron saqueos de mercados y tiendas. La algarada provocó la intervención de la Policía y del Ejército, cuyas fuerzas refrenaron los desórdenes con dureza. Los enfrentamientos cobraron decenas de muertos y heridos. El Gobierno, receloso ante la amenaza de un alzamiento popular de mayores proporciones, declaró el estado de sitio. Así, la violencia ejercida por las fuerzas del orden contuvo las protestas obreras en Lima y su puerto.

En el ámbito político, se efectuaron comicios por la presidencia de la República. Los principales contendientes en las elecciones fueron: el oficialista Antero Aspíllaga y el candidato de oposición Augusto B. Leguía. Durante las labores de escrutinio, cada bando denunció la alteración de los resultados, circunstancia que alentó el trámite de solicitudes a efectos de anular las elecciones. En tales circunstancias, el 4 de julio efectivos de la gendarmería protagonizaron un golpe de Estado que depuso a Pardo y proclamó como presidente a Leguía, quien asumió el mando supremo en calidad de presidente provisional. Investido de poder, Leguía decretó la disolución del Congreso, a la vez que convocaba a una Asamblea Nacional; ésta lo declaró presidente constitucional por un período de 
cinco años. El régimen que se inauguraba adoptó el nombre de "Patria Nueva», término que asociaba al flamante gobierno con el fin del control político de la oligarquía civilista y la incorporación de las clases medias para modernizar el país. Con este episodio comenzaba un nuevo período de nuestra historia republicana, cuya duración sería de once ańos.

Otro suceso acaecido en 1919 fue la irrupción de un movimiento de dimensión continental: la Reforma Universitaria. Influidos por el movimiento estudiantil gestado en la Universidad de Córdoba en 1918, estudiantes de San Marcos se pronunciaron públicamente en demanda de reformas institucionales.

La Universidad de San Marcos se hallaba regida por el Partido Civil. Las autoridades y un sector considerable del cuerpo docente estaban afiliados a este partido. Ello se advertía en la ausencia de renovación de las cátedras. Por otro lado, subsistían aún métodos escolásticos de enseñanza y era patente la obsolescencia en los contenidos de ciertas asignaturas. En la Facultad de Letras de San Marcos, se fraguaron acciones estudiantiles que impulsaron la Reforma Universitaria en junio de 1919.

El diario La Razón, dirigido por José Carlos Mariátegui y César Falcón, favoreció desde el inicio la causa universitaria. A partir de la edición del 25 de junio, informó de las demandas estudiantiles y, cotidianamente, publicó reportes sobre las principales deficiencias académicas y administrativas de cada una de las facultades. Los universitarios expusieron entre sus principales demandas: la orientación nacionalista de los estudios, el mejoramiento y la modernización de la enseñanza, la representación estudiantil en el gobierno de la Universidad (Consejo Universitario), el establecimiento de la cátedra libre y del derecho de remover a profesores incompetentes, la supresión de las listas de asistencia y la creación de becas que permitieran a los alumnos de escasos recursos económicos acceder a estudios universitarios. Además de lo reseñado, se exigía la jubilación de los profesores ancianos y el establecimiento de concursos; con esta última medida se haría posible la renovación de cátedras, permitiendo que jóvenes graduados fuesen atraídos hacia la enseñanza universitaria.

Los dirigentes de la Reforma abrigaban la confianza de que Leguía (nombrado en 1919 por la Federación de Estudiantes del Perú «Maestro de la Juventud») daría respaldo a sus peticiones, previsión que fue confirmada. A Leguía le interesaba que su gobierno recibiera la adhesión de los jóvenes; por otra parte, quería arrancar a los civilistas -sus adversarios políticos-, el control que tradicionalmente ejercían sobre la Universidad. Por estas consideraciones políticas, el presidente resolvió aprobar las demandas de los universitarios, coadyuvando, en una primera etapa, al éxito de la reforma.

De acuerdo con el testimonio de Luis Alberto Sánchez (1969), la Reforma Universitaria fue posible gracias a «la capacidad captadora y organizativa de Víctor Raúl Haya de la Torre, y la agresividad mordaz de Raúl Porras Barrenechea» (tomo 1, p. 144). Por su parte, Basadre (1981), estima que fue Porras su «verdadero inspirador» (p. 186).

\section{Fundación del Conversatorio Universitario}

Por iniciativa de Raúl Porras y de otros estudiantes de la Facultad de Letras de San Marcos, entre los que figuraron: Jorge Guillermo Leguía, Luis Alberto Sánchez, Guillermo Luna Cartland, Carlos Moreyra Paz Soldán, José Quesada, José Luis Llosa Belaunde, Víctor Raúl Haya de la Torre y Ricardo Vegas García, se fundó el Conversatorio Universitario. Éste comprendió un ciclo de ponencias tocantes a la época de la Emancipación, cuyo eje cronológico correspondió a los ańos 1800-1825. Dos fotografías de estudio, captadas en 1920, retrataron a ocho de sus integrantes ${ }^{1}$. De este núcleo, cuatro estudiantes presentaron comunicaciones en el Conversatorio: Leguía, Porras, Sánchez y Abastos. Cabe agregar que varios de los impulsores del Conversatorio participaron diligentemente en la Reforma Universitaria, movimiento en el que asumieron cargos directivos.

El objetivo central de su programa era, basándose en la información disponible, presentar otros ángulos de enfoque sobre el proceso ideológico y cultural de la Emancipación peruana, sus hechos y personajes. A tal efecto, se emprendería un balance de lo investigado y la elaboración de ensayos innovadores respecto a temas y aspectos insuficientemente explorados o desconocidos. Para materializar esta iniciativa, se programó un temario en el que sus organizadores

1 En ambas fotos aparecen Raúl Porras, Jorge Guillermo Leguía, Luis Alberto Sánchez, Ricardo Vegas García, Jorge Basadre, Guillermo Luna Cartland, Manuel G. Abastos y Carlos Moreyra Paz Soldán. 


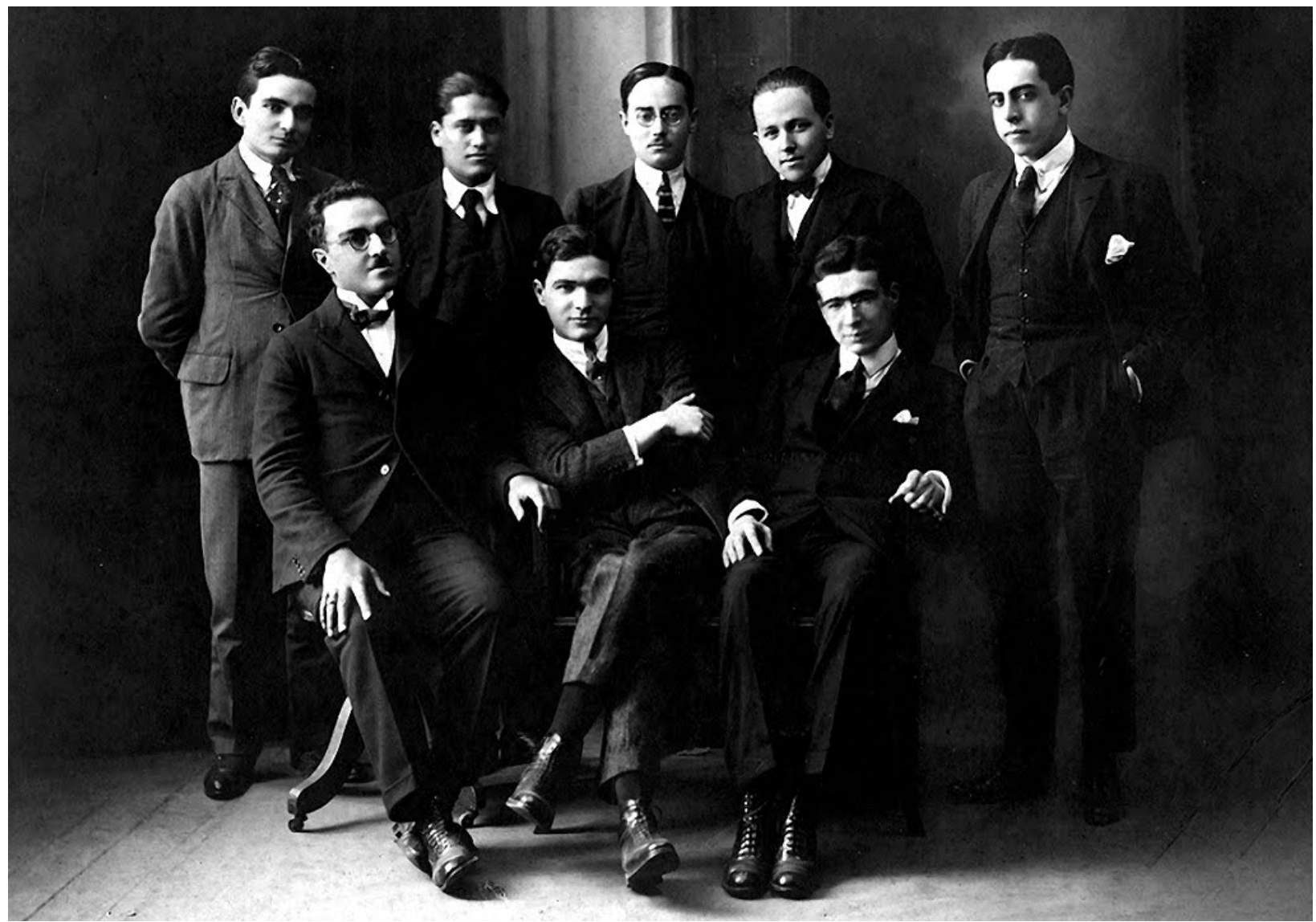

Foto1: Integrantes del Conversatorio Universitario: sentados (de izquierda a derecha): Guillermo Luna Cartland, Carlos Moreyra y Paz Soldán, Jorge Guillermo Leguía. De pie: Jorge Basadre, Manuel G. Abastos, Ricardo Vegas, Raúl Porras y Luis Alberto Sánchez.

expondrían las investigaciones históricas que venían pergeñando.

La circunstancia que definió el carácter del Conversatorio Universitario fue la proximidad del centenario patrio. Este factor, además de influir en la época escogida como materia de estudio, explicaría el contenido peruanista de los trabajos expuestos, concebidos desde un prisma liberal. Puede colegirse también que el Conversatorio creó un espacio de reflexión crítica que, desde los territorios de la historia, fue independiente y alternativo de las actividades oficiales que promovería el gobierno de Leguía para la celebración del centenario. Las investigaciones efectuadas por el grupo del Conversatorio, sin embargo, no influyeron en el discurso oficial sobre la independencia en 1921; antes bien, predominó la visión de Mariano Felipe Paz Soldán, historiador decimonónico, expuesta en su obra Historia del Perú independiente, publicada en Lima entre 1868 y 1874, y el discurso hispanista de la generación del Novecientos (Loayza Pérez, 2016, p. 31).

De otra parte, es de notar que el empeño renovador del Conversatorio iba de consuno con los ideales de la Reforma Universitaria. Sus promotores habían combatido arcaicos métodos educativos en la vieja universidad y querían sustentar las posibilidades de investigación para repensar la historia del Perú.

Sobre el tenor de los trabajos presentados, Basadre (1981) manifiesta el siguiente juicio: «La orientación de estas monografías no fue reaccionaria. No cayeron en la nostalgia colonialista, ni en la retórica patriotera, ni en el negativismo cerrado. Un liberalismo crítico e independiente las definió» (p. 205).

Gracias a los buenos oficios de Ricardo Vegas García, estudiante en San Marcos y redactor de $\mathrm{La}$ Prensa, se divulgaron los textos de las ponencias en el citado diario, a la sazón dirigido por Luis Fernán Cisneros. Asimismo, las tres primeras conferencias, que corrieron a cargo de Jorge Guillermo Leguía, 


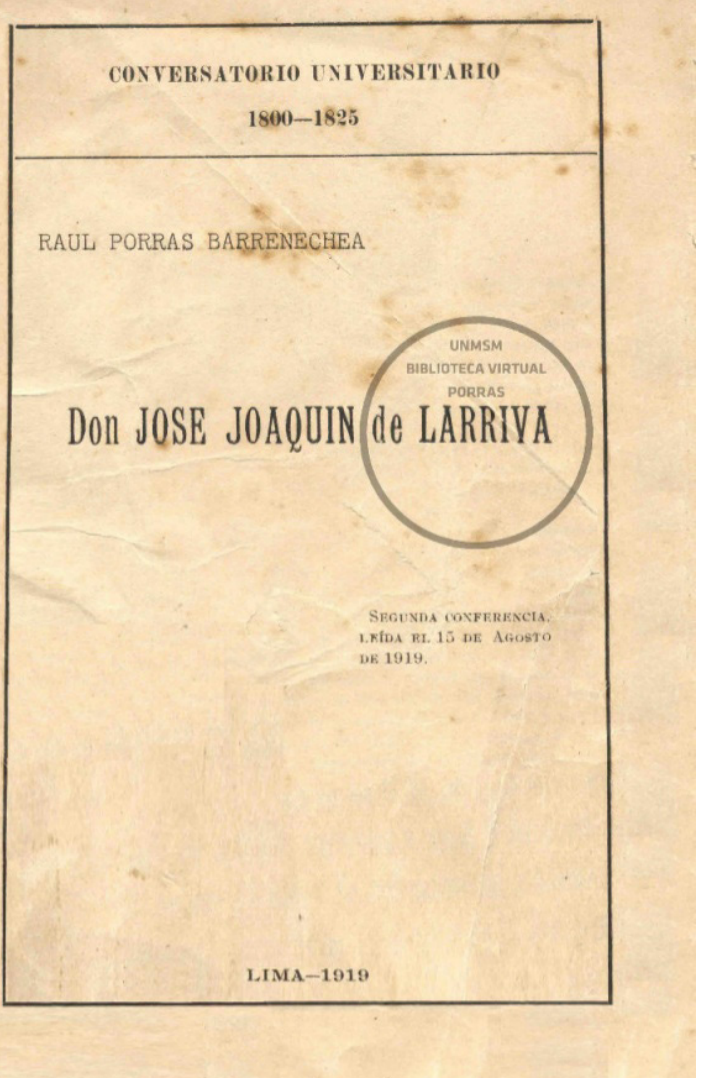

Foto 2: Publicación del Conversatorio Universitario: Don José Joaquín de Larriva, de Raúl Porras. Biblioteca del Instituto Raúl Porras Barrenechea.

Raúl Porras y Luis Alberto Sánchez, se imprimieron en folleto y fueron la simiente de futuros libros.

\section{Las ponencias}

La cronología de los temas abordados en el Conversatorio Universitario abarcó los primeros veinticinco años del siglo XIX, con la única excepción de la ponencia de Leguía, ambientada en la segunda mitad de la centuria decimoctava.

El ciclo de disertaciones se inauguró el 10 de junio de 1919 en la Biblioteca de la Federación de Estudiantes con la exposición de Jorge Guillermo Leguía, titulada "Lima en el siglo Xviı». En ésta, su autor exhibe un fresco social de la Ciudad de los Reyes, representada en sus aspectos materiales y espirituales durante la época que antecedió al proceso de independencia. El panorama que traza de la ciudad se

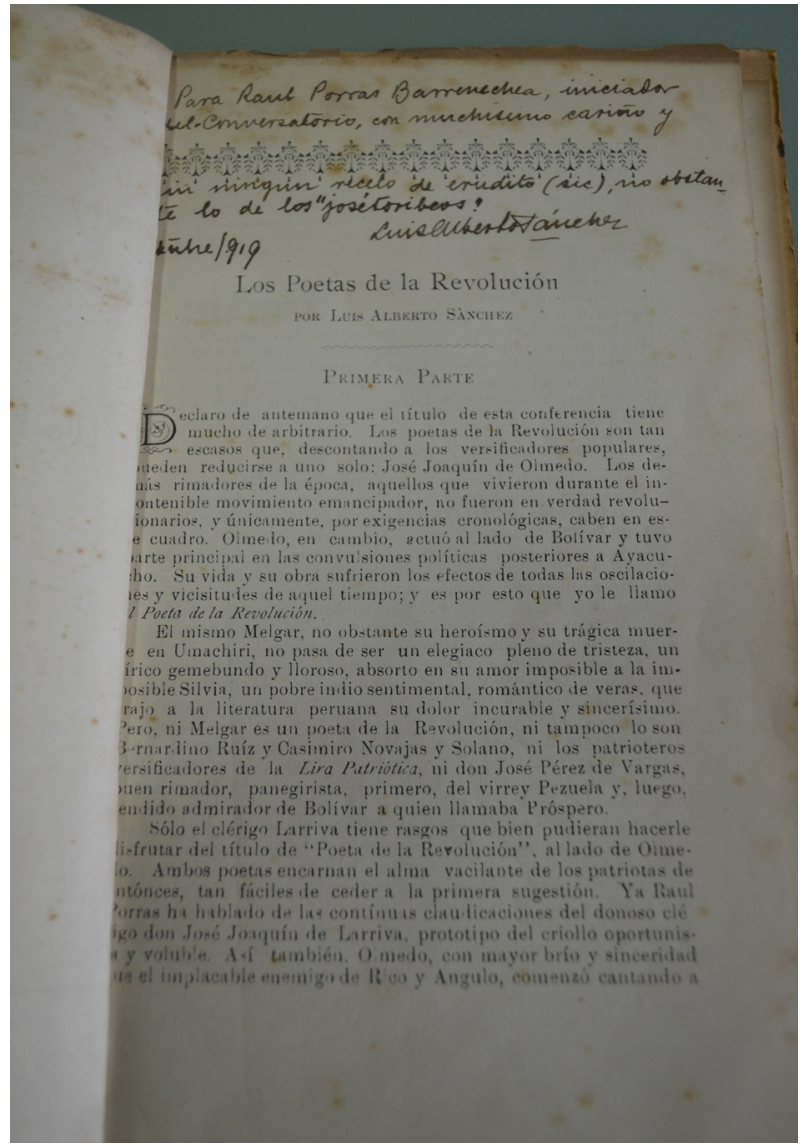

Foto 3: Ejemplar de Los poetas de la Revolución, de Luis Alberto Sánchez. Dedicatoria del autor a Raúl Porras.

«Para Raúl Porras Barrenechea, iniciador del Conversatorio, con muchísimo cariño y sin ningún recelo de erudito (sic), no obstante lo de los 'josétoribeos' Luis Alberto Sánchez. Octubre 1919». Colección Fondo Antiguo-Porras Barrenechea, Biblioteca Nacional del Perú.

sustenta en fuentes y artículos de la época, así como en estudios contemporáneos ${ }^{2}$. Es preciso subrayar de este trabajo el enfoque multidimensional desde el que aborda a su objeto, perspectiva que considera componentes de la geografía, de la cultura material y de la idiosincrasia y mentalidad en Lima bajo esa centuria. El autor no se ocupa de los contornos políticos e institucionales, que eran asuntos de atención preferente en la historia peruana; su análisis se centra

2 Entre los primeros hemos de citar trabajos científicos publicados en Mercurio Peruano, los estudios del naturalista Tadeo Haenke, las Memorias del general Guillermo Miller y las relaciones de viajeros europeos (Amédée-François Frézier y Jorge Juan y Antonio de Ulloa). Las fuentes secundarias están integradas por los estudios de José Toribio Polo y de Pablo Patrón, el Diccionario histórico biográfico del Perú, de Manuel de Mendiburu, Tradiciones peruanas, de Ricardo Palma, entre otras obras. 
en el escenario urbano y las creencias y costumbres de sus pobladores. En tal virtud, el trabajo de Jorge Guillermo Leguía corresponde al área de la historiografía designada como historia de la vida cotidiana.

En la mentada exposición, Leguía, tras referir las características territoriales y el entorno geográfico de la ciudad fundada por Pizarro, expone coloridas descripciones de su fisonomía material. Aquí alude al «definido aspecto oriental» de la capital del Virreinato. Tal carácter provenía de los elevados miradores de las casas y de las macizas torres que evocaban los minaretes y las cúpulas de las mezquitas. Ello, aunado a los balcones de celosía y a la costumbre de colocar tiestos de flores en los alféizares de las ventanas, asemejaba Lima a las ciudades agarenas, conforme con lo descrito por Leguía.

De otro lado, el ponente avista que la ciudad, en su aspecto material, conjuntaba "caracteres de grandeza y signos de rusticidad arquitectónica» (Leguía, 1921, p. 11). Esta descripción estriba en el lujo palaciego de las casas pertenecientes a la nobleza y la exuberancia churrigueresca de los templos, en contraste con los extendidos muros de los conventos y monasterios y los macizos contrafuertes de las iglesias. Refiere la suntuosidad interior de las moradas, cuyos propietarios no escatimaban gastos en lujos de este carácter. Para Leguía (1921), ello era expresión palmaria del «espíritu epicureísta de los peruanos capitolinos» (p. 19). Agrega, sin embargo, que la grandeza de la arquitectura de Lima decayó de resultas del terremoto de 1746. Luego de su reconstrucción material, las «tres veces coronada villa» no recuperó la suntuosidad de antaño, puesto que la condición hacendaria de sus habitantes no permitió sufragar crecidas sumas para su reedificación.

En el horizonte social, el joven historiador apunta el nuevo perfil de los limeños en lo que respecta a su espíritu religioso. En contraste con el siglo precedente, que se distinguió por el arraigado sentimiento de religiosidad, la ocurrencia de una desgracia colectiva o de algún suceso infausto producía «el fenómeno de agitar en las conciencias las dormidas aguas de la fe, y de inundar con las hirvientes olas de la creencia los fríos peñascos de la indiferencia espiritual» (p. 21). Era en circunstancias semejantes que los limeños ofrendaban oraciones públicas y salían en procesión; empero, una vez superados los aciagos incidentes «olvidaban sus preocupaciones devotas y daban ex- pansión a sus tendencias voluptuosas y a sus hábitos epicureístas» (p. 22). Estas costumbres, consignadas por Leguía, se observaban en las diferentes capas de la sociedad y en la vida de los eclesiásticos, tal como fuera testimoniado por los viajeros españoles y franceses del siglo XviII.

Por otra parte, pondera en esta disertación el ánimo festivo de los limeños de antaño. Aparte de las fechas conmemorativas del calendario religioso, era motivo de grandes celebraciones ciertas noticias políticas provenientes de Madrid; también lo era la entrada de un virrey a la capital. Estas festividades, en las que participaban tanto los nobles como gentes de sectores populares, se veían interrumpidas sólo, y por breve espacio, ante un suceso infortunado. Una vez remontado, la sociedad limeña proseguía su vida sibarítica. Lo antedicho revelaba, a juicio del historiador, un ambiente "de inercia material y moral», que alcanzaba también a los artesanos y jornaleros. En una sociedad como la descrita, proclive a la ociosidad, nació el chisme, añade el expositor.

Es plausible la crítica planteada por Leguía al concepto conforme con el cual la sociedad limeña del siglo XVIII se distinguió por su despreocupación hacia la cultura. En ese sentido, propuso que era menester considerar las contribuciones intelectuales y la sensibilidad estética de la población urbana en las proximidades de la independencia.

Finalmente, relata el vuelco que obra en la mentalidad de los criollos. Este grupo social, conocedor del pensamiento ilustrado, a cuyos autores leía con habitualidad, se hallaba excluido de los cargos y beneficios en la administración colonial. Además, los criollos comerciantes se veían impedidos de traficar libremente con los puertos europeos a causa de las restricciones impuestas a su sector; asimismo estaban obligados al pago de gravosos impuestos. Esta situación engendraba en su espíritu ideas y sentimientos de libertad:

Latente se halla el recuerdo de la emancipación norteamericana. Otros criollos abrigan las mismas ideas y ocultan propósitos idénticos. Y él, hombre de convicciones, hombre de determinaciones viriles, hombre de fe, se impacienta por la tardanza de la nueva era de libertad y de independencia. (Leguía, 1921, p. 37). 
Dos meses después de esta exposición, el 15 de agosto, se efectuó la segunda charla del Conversatorio Universitario. Ésta abordó la vida, la obra y el tiempo del escritor satírico limeño José Joaquín de Larriva (1780-1832), y tuvo por disertante a Raúl Porras Barrenechea.

El expositor abrió su comunicación precisando, en primer término, que ésta no versaría sobre ningún personaje o acontecimiento que tuviera un carácter definitivo en el período estudiado. Dice de Larriva que no ostentaba la personalidad del virrey Abascal o del clérigo y educador Rodríguez de Mendoza; tampoco intervino en los sucesos de la independencia, en contraposición a José Faustino Sánchez Carrión y Bernardo de Monteagudo. Además, en lo que concierne a la calidad literaria, no alcanza la estatura de José Joaquín de Olmedo y Mariano Melgar. ¿En qué reside, entonces, el interés por estudiar la vida y circunstancia de este clérigo y escritor? Porras esboza una caracterización preliminar del personaje:

Representativo del peruano de su época, acaso no muy desemejante del actual. Del peruano del segundo decenio del siglo diecinueve, extraño en su mayor parte a la revolución, aun a la misma que se fraguaba en Lima, ridículamente fiel a Fernando VII, cortesano de los virreyes, componedor habilísimo de todos los negocios públicos en las charlas de café y de las esquinas y espectador desde su casa del menor asomo de alboroto, conspirador de palabra, haragán con sueldo del Estado, doctor de la Universidad y portador de la agudeza más picante y oportuna en los labios. Representativo del limeño de su época, de los que no se convencieron de la independencia hasta que se dieron con el ejército de San Martín en las calles, pero que al día siguiente gritaban con la mayor sinceridad y buena fe del mundo: ;Viva la patria! ¡Mueran los godos! Representativo del ciudadano ingobernable, merecedor en parte de los dicterios de Le Bon, que al año de la patria clamaría contra el Protector y luego por Bolívar y después contra Bolívar. Encarnación de ese espíritu nacional, demasiado analista y destructor, incapaz de grandes obras, pero certero en críticas menudas, descontento mordaz e irrespetuoso. Tipo del criollo hábil para la intriga e inútil para la acción, lleno de audacia moral y de irresistible cobardía física (...) Representativo étnico, del criollo en el que se fundieron la apatía indiana con el gracejo andaluz (Porras Barrenechea, 1919, pp. 17-18).
Como queda expresado, la elección del protagonista de esta conferencia reside en los caracteres de su personalidad, no sólo representativa de la época de transición de la Colonia a la República, sino que, al propio tiempo, personifica al arquetipo del criollo limeńo oportunista de la historia del Perú independiente.

Acerca de la trayectoria de Larriva, Porras informa que el período de su mayor actividad transcurre en los primeros veinticinco ańos del siglo XIX, época de acrecentado prestigio de la vida intelectual en el Virreinato. La intensa actividad cultural de las postrimerías de la Colonia se manifestaba en la difusión de las ideas europeas, la circulación de libros y la publicación de Mercurio Peruano. Larriva se educó en el colegio de San Carlos, centro de la cultura occidental a fines del siglo xviII, en donde tomó contacto con las ideas liberales, a las que era afín. Al concluir su educación humanista en el convictorio carolino, cursó estudios en la Universidad de San Marcos, en la que adquirió prestigio como latinista. Concluida su formación, Larriva se decantó por la vida religiosa. Porras anota que, como revelara su vida ulterior, hubo de adoptar el oficio eclesiástico no por vocación sino orientado por las inclinaciones de su tiempo.

En 1807, cuando se desempeñaba como maestro colegial en San Carlos, pronunció su elogio de Abascal, figura política que admiraba con ardor. En reciprocidad, el Marqués de la Concordia le hubo de conceder el título honorífico de Capellán del Regimiento de la Concordia. Entre los años 1811 y 1814, Larriva editó varios periódicos en Lima, todos ellos adictos al virrey Abascal.

En su ensayo, Porras pone de relieve la actividad periodística del clérigo limeño. En sus escritos publicados en El Cometa y El Argos Constitucional, Larriva vertía su espíritu satírico. Primordialmente, destacan sus colaboraciones en El Investigador, periódico publicado de 1813 a 1814 . Porras apunta de este periódico — que se componía de cuatro páginas impresas- las noticias concernientes a la vida en Lima ${ }^{3}$.

3 La ciudad que se refleja en este periódico disuena de las descripciones que autores decimonónicos retrataron de la capital del Virreinato. A este propósito, Porras escribe: «No era Lima la ciudad encantada, mística y olorosa que nos pinta la colorista historia de Vicuna Mackenna. La ciudad que brota de estas páginas era pobre, sucia, destartalada y oscura. El incienso no era suficiente para dominar el hedor de las calles, convertidas en muladares, por la falta de vigilancia y la indiferencia de todos" (Porras Barrenechea, 1919, p. 23). 
El periódico no se circunscribía a retratar el abandono físico de la ciudad, sino también las deficiencias que se percibían en el orden moral; por ejemplo, los inacabables y dilatorios trámites en las oficinas públicas, el desorden y el fraude administrativos, etcétera. El Investigador cumplió una tarea edificante en aras del progreso cultural, procurando extirpar inveterados defectos sociales y, por cierto, corregir las pasividades vecinales. La pluma de Larriva, encubierta bajo innúmeros seudónimos, fustigó las costumbres de la vida social limeña. Conviene advertir en este apartado las indagaciones pioneras de Porras acerca de las publicaciones periodísticas de fines de la Colonia, materia que estudiaría exhaustivamente en El periodismo en el Perú, trabajo publicado dos años después .

Las variaciones de postura exhibidas por Larriva se manifestaron, verbigracia, en su actitud hacia Bolívar, a quien en 1826 dedicó un encendido elogio. Empero cuando la Gran Colombia aprestaba sus fuerzas contra el Perú, Larriva trocó el elogio en diatriba. Sin juzgar negativamente las contradicciones en su proceder, Porras (1919) pondera:

La evolución política de Larriva es perfectamente justificable. Fue de los espíritus que, a pesar de su liberalismo, no comprendieron la independencia, pero que tuvieron que capitular ante la realidad, como los generales de Espańa capitularían años más tarde en Ayacucho. (p. 30)

Porras Barrenechea aprecia la obra de Larriva como precursora del peruanismo literario. En lo formal, acusa rasgos de la literatura colonial, a la vez de incorporar formas modernas. Larriva es un personaje bisagra entre el coloniaje y la República en el terreno de la literatura y en la política. Asimismo, fue pionero del periodismo satírico republicano, al haber fundado periódicos que serían el modelo de la prensa de este género que se cultivó desde entonces. En estas cualidades reside su valor en la historia literaria del Perú.

La tercera conferencia del Conversatorio Universitario fue leída el 22 de septiembre. Con el título de Los poetas de la Revolución, Luis Alberto Sánchez expuso un estudio de los versificadores del período de la Emancipación, analizando, sobre todo,

4 El estudio de Porras se publicó en la edición especial de la revista Mundial con motivo del centenario de la Independencia. Lima, 28 de julio de 1921. la vida y obra de José Joaquín de Olmedo (17801847). En dicha monografía realiza un abordaje crítico de la poesía que se compone en la época que América es sacudida por el grito de libertad. El autor ventila puntos de vista originales y discuerda de los juicios expresados en estudios literarios precedentes. En tal sentido, Sánchez que, aún no había cumplido los diecinueve años de edad, critica y rectifica a historiadores peruanos de renombre (Manuel de Mendiburu, José Toribio Polo). Cabe añadir que, en una aproximación general a la Emancipación peruana, Sánchez (1919) opina que es verdad que «no escasearon en nuestra patria las insurrecciones; pero nuestra colaboración al movimiento emancipador fue, en realidad, pobrísima» (p. 55). Al mismo tiempo, asegura que el Perú no cuenta con una figura representativa, puesto que las grandes personalidades de la independencia fueron extranjeras.

Asimismo, en el panorama literario, comprueba la escasez de bardos, y sostiene que, entre ellos, únicamente José Joaquín de Olmedo puede ser reputado como tal, escribiendo que: «Su vida y su obra sufrieron los efectos de todas las oscilaciones y vicisitudes de aquel tiempo; y es por esto que yo le llamo el Poeta de la Revolución» (Sánchez, 1919, p. 47). Sánchez no reconoce en escritores como Mariano Melgar, Bernardino Ruiz y Casimiro Novajas y Solano a poetas de la revolución. La única excepción que admite es la de Joaquín de Larriva, cuya obra poética ostenta rasgos comunes con la de Olmedo, al tiempo de coincidir en la fragilidad de sus convicciones políticas.

Una nota que estampa la obra de los poetas de la independencia es su adaptación a las nuevas circunstancias. De esta guisa, quienes habían celebrado los triunfos realistas, ulteriormente cantaron alabanzas a San Martín. Y, bajo el gobierno de Bolívar, compusieron versos aduladores al libertador caraqueño. Entre sus autores nomina a José María de Pando y José Pérez de Vargas; pero la obra que, a juicio del expositor, merece pasar a la posteridad es el canto $A$ la Victoria de Junín de José Joaquín de Olmedo.

Acerca de la relevancia literaria y política de Olmedo, escribe Sánchez (1919:

Estrechamente vinculada con la vida política, la poesía de los últimos años de la Colonia y los primeros de la República, refleja las múltiples y contradictorias influencias sociales, todos los aconteci- 
mientos que, a la sazón, tenían suspenso el ánimo de los suramericanos. Ya canta a Bolívar vencedor y denigra al derrotado hispano, o ya, por el contrario, envalentonado con algún triunfo realista, la emprende contra los insurrectos y besa las plantas de los magnates peninsulares. Es por eso que entre la turba de aquellos poetas, surge Olmedo no sólo como una figura literaria de primer orden, sino como un personaje político de los más principales. Es, y así podemos caracterizarlo definitivamente, nuestro Bolívar literario. (p. 60)

Sánchez compendia el curso vital del poeta guayaquileño, e informa que su incursión literaria data de 1807. En su producción temprana, Olmedo dedicó poesías al virrey Abascal y una elegía a la muerte de la princesa de Asturias, doña María Antonia de Borbón. De su actividad política evoca que, en calidad de representante de Guayaquil, asistió a las Cortes de Cádiz; en América ensanchó su experiencia política integrando la Junta de Gobierno de Guayaquil y con su elección como representante del Congreso Constituyente del Perú, en 1822.

Anota Sánchez su censura inicial a la ambición de Bolívar, aunque más tarde, durante la campaña bolivariana en el Perú, se tornó en devoto admirador del general venezolano. Olmedo sirvió a su gobierno; pero cuando Bolívar declaró la guerra al Perú, escribió una carta de recusación el 20 de noviembre de 1828 .

La expresión consumada del espíritu bolivarista de Olmedo fue su composición A la Victoria de Junín, de 1825, que a juicio de Sánchez (1919) «es demasiado artificiosa y aduladora» (p. 68). El tono general de esta poesía le merece una valoración menor que otras composiciones como odas Al Árbol y, sobre todo, el canto A Miñarica, que estima como la obra capital y consagratoria del poeta. En ésta celebra la victoria militar del general Juan José Flores en la guerra civil en Ecuador. Empero, como ocurriera antes en su fluctuante recorrido político, Olmedo conspiró contra Flores y fue responsable de su derrocamiento. A continuación, integraría el gobierno provisorio y, más tarde, lanzaría su candidatura a la presidencia de la República en 1845, que no alcanzó. En una carta a su amigo Andrés Bello, escrita en Guayaquil en 1847, expresa, como tantos otros actores políticos de su época en América, su decepción por la obra de la Independencia.

En una apreciación de su obra poética, Sánchez (1919) concluye:
Fue un orador en verso, un orador para muchedumbres delirantes, para muchedumbres electrizadas, para muchedumbres convulsas. Sólo de cuando en cuando, la nota íntima vibra en su poesía; mas, se pierde ahogada por el clangor de tantos clarines y por el estrépito de los combates. (p. 77)

Se observa en los juicios de Sánchez concernientes a la poesía de ese período y, en particular, a la literatura de Olmedo, la impronta de su maestro José de la RivaAgüero, cuyas ideas en torno a esta temática expuso en Carácter de la literatura del Perú independiente.

La cuarta conferencia del Conversatorio estuvo a cargo de Manuel G. Abastos, cuyo tema fue: «La influencia ideológica de la revolución peruana de la independencia», materia sobre la que disertó el 3 de noviembre. En esta comunicación, Abastos sostiene que las ideas políticas y jurídicas nacidas de la Ilustración ejercieron honda influencia en la sociedad americana, en particular entre los criollos. Su influjo decisivo alcanzó principalmente al Perú, país en el que circularon obras del pensamiento racionalista y científico europeo. Estos escritos sedimentaron la ideología de la revolución independentista.

Asegura que ésta fue, en general, aristocrática por cuanto los primeros insurgentes se habían educado en las ideas liberales. En América, las elites ilustradas consumaron la independencia. Se trató de grupos numéricamente reducidos que pugnaron por cambios sociales y políticos; su prédica si bien atrajo prosélitos ejerció apenas influencia en las masas populares. En vista de tal referencia, los indígenas, mestizos y negros, «impermeables a las doctrinas», sirvieron a los bandos en disputa, pero, a la postre, se plegaron a los patriotas.

Además de ello, hubo otros factores que impulsaron la independencia americana; entre ellos menciona las «pasiones anárquicas» y los «odios atávicos» engendrados por la situación de fatigante servidumbre. De tal suerte, dice:

El esfuerzo revolucionario de los criollos, los únicos que sońaron en la nueva unidad política, recibe caudal no escaso de esta grave situación de espíritu. Pero lo esencial está en la rebeldía del grupo selecto, en cuyos individuos coinciden el despecho y el rencor desbordados, con el claro concepto de sus propios derechos desconocidos. (Abastos, 1919, p. 2) 
En consideración de este autor, la revolución peruana adquiere, desde el último tercio del siglo XviII, el carácter de una "cruzada ideológica». El foco de enseñanzas liberales era el Real Convictorio de San Carlos, regido por el sacerdote chachapoyano Toribio Rodríguez de Mendoza. De ahí que el conferencista distinga dos etapas en la independencia del Perú: la educacional y la etapa de acción. En la primera, se despliega la obra de los ideólogos precursores, entre 1787 y 1812, tiempo caracterizado por la difusión de ideas revolucionarias. Por entonces, los maestros no concibieron el separatismo ni el orden republicano; en tanto que sus discípulos, inspirados por pensamientos y hechos acaecidos en el continente, se oponen a la reaccionaria monarquía española de 1814. Asimismo, asegura que la emancipación nacional es el efecto histórico de la cultura propagada por el Estado recientemente instituido en tierras americanas. Declara el dicente que es premisa incuestionable sostener que los introductores del enciclopedismo y del jacobinismo teórico no se propusieron fundar la república en el Perú. Por el contrario, la generación educada en el Convictorio de San Carlos sí fue republicana, por cuanto la convicción doctrinaria se consustancia con una realidad continental.

El autor se interroga hasta qué grado las ideas monárquicas inculcadas por España habían arraigado en América. Responde que en el Perú estas ideas habían enraizado por el hecho de que Lima fuera asiento del poder virreinal y de la Real Audiencia.

De otro lado, postula la correlación necesaria entre el problema ideológico y la múltiple causalidad de la independencia. A tenor de este planteamiento, sostiene que si las ideas francesas penetraron en la mentalidad americana fue porque existía una actitud proclive a la recepción de éstas. Es decir, la influencia de las ideas políticas no podría concebirse sin un previo cambio de pensamiento. Existía un contexto auspicioso para la difusión de la cultura y de la ciencia en el Nuevo Mundo, merced al liberalismo propulsado por Carlos III.

Esclarece que las ideas liberales no provinieron exclusivamente de Francia. Abastos cita, por ejemplo, la repercusión ideológica de autores peninsulares, entre los que menciona a Feijóo, Aranda, Quintana y Jovellanos. Sostiene que el liberalismo peninsular definió dos matices: el laicismo del Estado y el fin de «desautocratizar» la monarquía. Es por obra de la Revolución de 1789 que se replantea en España la concepción del Estado y se promueve la fundación de una república de corte francés. Tal fue el caso de los conspiradores de San Blas en 1796. De esta escuela brota la Constitución gaditana de 1812 que tanta influencia irradiaría sobre el pensamiento americano.

Sustenta, asimismo, que en América se perfilan la etapa de la fe y la etapa crítica. La primera es propia de la época colonial, en la que prevaleció la escolástica y donde las verdades superiores se fundaban en las Sagradas Escrituras. Es desde la lectura de autores como Descartes y Locke que el pensamiento racional se expande en América. A partir de entonces, se infunde en el continente y en el Perú un espíritu crítico que condena el pasado y su ominosa estela de injusticia. El pensamiento racionalista de los ilustrados abre surcos para la reforma constitucional de la monarquía y, después, rotura el terreno de la emancipación política.

La contribución esencial de esta comunicación estriba en que su autor desgrana las influencias ideológicas de la Independencia, entre las que destaca, conjuntamente con las ideas francesas, las aportaciones del pensamiento liberal hispano y la huella de la Constitución de 1812. De la misma manera, Abastos elucida la formación de una actitud crítica entre los criollos americanos que constituyó el fundamento de la guerra separatista.

$\mathrm{Al}$ ańo siguiente de las exposiciones que acabamos de revisar, se emprendió un segundo ciclo del Conversatorio Universitario. En esta ocasión, fueron dos las conferencias leídas: Jorge Guillermo Leguía ofreció una exposición sobre Toribio Rodríguez de Mendoza, y Raúl Porras sustentó la conferencia titulada «San Martín en Pisco», con motivo del centenario del desembarco de la expedición libertadora en playas iqueńas, ocurrido en septiembre de $1820^{5}$.

En síntesis, los aportes del Conversatorio Universitario al estudio de la independencia del Perú se expresaron en el acervo documental explorado: folletos, relaciones de viajeros y, sobre todo, periódicos coetáneos. De otra parte, destacan las indagaciones sobre actores históricos cuyo rol no había sido convenientemente apreciado. No centraron su atención en personajes de relieve militar o político, sino en figuras de la vida civil cual escritores e ideólogos. Por lo que respecta a la participación de los grupos sociales en el movimiento de independencia, pusieron el acento en los criollos, sector educado en las ideas ilustradas, que

5 El texto se publicó en La Prensa, Lima, 9 de septiembre de 1920, pp. 1-2. 
insatisfechos por no ejercer cargos encumbrados en la administración colonial y limitados en su actividad mercantil por razón del monopolio comercial, impulsaron la causa libertaria. Así también, los trabajos del Conversatorio caracterizaron el proceso de independencia como una revolución, en virtud de las acciones separatistas que se forjaron en América contra la dominación espańola, resultado de lo cual fue un cambio de administración. El concepto de «revolución de independencia», empleado por el historiador chileno Benjamín Vicuña Mackenna en su obra La revolución de la independencia del Perú desde 1809 a 1819 (1860), tuvo desde los días del Conversatorio Universitario aceptado uso en la historiografía peruana ${ }^{6}$.

\section{Trascendencia cultural}

Las ponencias del Conversatorio Universitario merecieron la atención de José Gálvez en el artículo publicado en la revista Mundial el 28 de julio de 1921. El poeta limeño celebraba tan valioso esfuerzo intelectual, y opinaba acerca del sentido de la renovación de los estudios históricos que la nueva pléyade debería alumbrar:

Hoy mismo puede decirse que a este afán nacionalista se deben las contribuciones valiosísimas de Sánchez, de Leguía y de Porras, a nuestra historia, que ojalá sea hecha con cierto sentido de orgullo y de simpatía para reaccionar contra el fiero criterio de odiosidad, con que por lo general nuestros historiadores y colectadores de datos, han contribuido, sin proponérselo tal vez, pero eficazmente, a empequeńecernos y desprestigiarnos. Precisa, para la formación del alma nacional que la Historia del Perú, se haga con espíritu de justicia, pero con cordialidad generosa, sin diatriba y sin escándalo. Juzguemos a los hombres en el plano que les corresponde, dentro del ambiente en que se movieron y con el séquito ideológico que los informó, determinándolos muchas veces. Esta labor, a la vez de amor y de justicia, corresponde esencialmente a este grupo, a quien emplazamos para que en el próximo grandioso centenario del año 24 , cumplan tan alto y noble compromiso. (J.G., 1921)

6 Acerca de los aportes históricos de la obra de Vicuña Mackenna y su recepción por la historiografía, véase V. Peralta Ruiz, «La revolución de la independencia del Perú (1860) de Benjamín Vicuña Mackenna en la historiografía peruana”, en Histórica vol. xxxviI, n. ${ }^{\circ} 1$ (2013), pp. 109-133.
En relación con el juicio de Gálvez, debe precisarse que, efectivamente, la contribución del Conversatorio Universitario se manifestó tanto en el esclarecimiento del ambiente que antecedió la gesta emancipadora cuanto en la perspectiva de análisis. Su ponderación crítica contrastaba con aquellas obras que no habían destacado con suficiencia la contribución peruana a la independencia. Los expositores se adentraron en el tiempo de la Emancipación desde distintos abordajes; entre ellos el análisis de la producción literaria y periodística y la exégesis ideológica. Su genuina aportación, sin embargo, no se plasmó en una obra de hechura colectiva que revisara y corrigiera ciertos tópicos historiográficos. Ello no obstante, los jóvenes investigadores prestaron valiosa contribución a la bibliografía peruana. A este respecto, es oportuno traer a colación que en el Salón América de la Biblioteca Nacional, Porras y sus condiscípulos trabajaron en el registro y catalogación de la Sección «Papeles Varios», conformada por colecciones de folletos coloniales y republicanos. Se trataba de un conjunto de ejemplares raros y únicos que, de manera infausta, se perdieron irreparablemente con el incendio que devoró la Biblioteca Nacional de Lima el 10 de mayo de $1943^{7}$.

Por otro lado, cada uno de los participantes del Conversatorio trazó su propio derrotero en la investigación histórica. Concurrieron en su interés común por el siglo XIX. Por esta senda, Sánchez amplió su investigación sobre la poesía de aquel tiempo, dando a las prensas en 1921 su libro Los poetas de la Colonia, que recibiría elogiosos juicios de la crítica. De su lado, Porras Barrenechea ahondaría sus estudios sobre los satíricos limeños y dedicaría prolijos y documentados ensayos alrededor de las personalidades de José Faustino Sánchez Carrión y Mariano José de Arce. Aparte de ello, realizaría - como queda dicho- una indagación primicial sobre la historia del periodismo en el Perú. Finalmente, Jorge Guillermo Leguía consagró obras a figuras representativas de la Emancipación y la República temprana, como las biografías de Toribio Rodríguez de Mendoza en El precursor (1922) y Manuel Lorenzo de Vidaurre (1935); además escribió el opúsculo Simientes para un ensayo sobre la guerra de la independencia hispanoamericana (1928). Subsecuentemente, cuando

7 Véase Raúl Porras Barrenechea, «Pasión y muerte de la Biblioteca Nacional", en Mercurio Peruano, vol. 194, n. ${ }^{\circ} 25$ (1943), pp. 208-209. 
ejercía la dirección del Museo Bolivariano, editó el Boletín de esta institución entre 1928 y 1930, en cuyos ejemplares divulgó documentos y estudios sobre la Independencia. La prematura muerte de Leguía, antes de que cumpliera los treinta y seis años de edad, acaecida en 1934, dejó truncada una obra que fue expresión de sus grandes cualidades de historiador.

\section{Conclusión}

La inauguración de las actividades del Conversatorio Universitario, en junio de 1919, correspondió a los días en que el movimiento estudiantil en San Marcos desenvolvía una amplia labor que demandaba la reforma de la Universidad. Quienes promovieron el Conversatorio tuvieron una participación muy activa y notoria en aquella movilización. De ahí que el referido suceso académico no sólo revelara su temprana erudición y madurez de juicio, sino que fue un cauce efectivo de renovación de los estudios históricos en el Perú. Tal iniciativa era un deber primordial para este círculo universitario en razón de las críticas que había enfilado, en muchos casos, a los catedráticos de San Marcos, censurados por no fomentar la investigación y no actualizar los contenidos de sus asignaturas.

La principal contribución del Conversatorio se halla en la perspectiva crítica que emanó de sus conferencias, cimentada en el cotejo de una panoplia de fuentes. Asimismo, sus autores incursionaron en temáticas poco exploradas, de las que ofrecieron sustanciosos análisis. Con ello, los trabajos leídos abrieron nuevas rutas en la investigación histórica.

En otro aspecto, el Conversatorio Universitario representó la primera manifestación paladina de los intelectuales de la "Generación del Centenario", bautizada así por José Gálvez en referencia a que su aparición ocurrió en los días que se conmemoraba el centenario de la independencia. Esta generación labró honda huella en el estudio de la realidad nacional. De tal suerte, las aportaciones sustantivas desde las humanidades y las ciencias sociales fundaron la visión contemporánea del Perú. Y en el ámbito de la política se promovió la gestación de los primeros partidos de masas de su historia: el APRA y el Partido Socialista del Perú.

Hoy, a escasos años de la conmemoración del Bicentenario de la Independencia, interesa tender la mirada hacia esta hornada de entusiastas y comprometidos jóvenes que, sin contar con respaldo o auspicio institucional alguno, materializó un proyecto germinal de investigación sobre una parcela del pasado en que la nación peruana se abría camino hacia su vida independiente.

\section{Bibliografía}

Аваstos, M. (1 de diciembre 1919). El Conversatorio Universitario. La influencia ideológica de la revolución peruana de la independencia. La Prensa (edición de la tarde), p. 2.

BASADre, J. (1981). La vida y la historia. Ensayos sobre personas, lugares y problemas (2a ed.). Lima: Industrial Gráfica.

Basadre, J. (2005). Historia de la República del Perú (18221933) (9a ed., tomo 14, pp.14-29). Lima: Empresa Editora El Comercio.

Gálvez, J. (28 de julio de 1921). El Conversatorio Universitario. Mundial.

Leguía, J.G. (1921). Lima en el siglo XVIII. Ciudad de los Reyes: Euforión.

Loayza Pérez, A. (2016). Del Perú mestizo a la idea crítica. Historiografía, nación e independencia, 19201980. En Loayza Pérez, A. (editor). La independencia peruana como representación. Historiografía, conmemoración y escultura pública (pp. 25-60). Lima: Instituto de Estudios Peruanos.

Peralta Ruiz, V. (2013) La revolución de la independencia del Perú (1860) de Benjamín Vicuña Mackenna en la historiografía peruana. Histórica, 1 (37), 109-133.

Porras Barrenechea, R. (1919). Don José Joaquín de Larriva. Lima: Imprenta SS.CC.

Porras Barrenechea, R. (mayo 1943). Pasión y muerte de la Biblioteca Nacional. Mercurio Peruano, 25 (194), 202-213.

SÁnchez, L.A. (1919). Los poetas de la Revolución. Lima: Imprenta «SS.CC.»

Sánchez, L.A. (1969). Testimonio personal. Memorias de un peruano del siglo $X X$ (tomo 1). Lima: Ediciones Villasan.

SÁnchez, L.A. (1988). La generación del centenario. En Sánchez, L.A. La vida del siglo (pp. 3-10). Caracas: Biblioteca Ayacucho. 